Article

\title{
Transferless Inverted Graphene/Silicon Heterostructures Prepared by Plasma-Enhanced Chemical Vapor Deposition of Amorphous Silicon on CVD Graphene
}

\author{
Martin Müller ${ }^{1}$, Milan Bouša ${ }^{2}$, Zdeňka Hájková ${ }^{1}{ }^{1}$, Martin Ledinský $^{1}$, Antonín Fejfar ${ }^{1}$, \\ Karolina Drogowska-Horná ${ }^{2}$, Martin Kalbáč ${ }^{2}$ and Otakar Frank ${ }^{2, *(D)}$ \\ 1 Institute of Physics, Czech Academy of Sciences, Cukrovarnická 10, 16200 Prague, Czech Republic; \\ mullerm@fzu.cz (M.M.); hajkovaz@fzu.cz (Z.H.); ledinsky@fzu.cz (M.L.); fejfar@fzu.cz (A.F.) \\ 2 J. Heyrovský Institute of Physical Chemistry, Czech Academy of Sciences, Dolejškova 2155/3, 18223 Prague, \\ Czech Republic; milan.bousa@jh-inst.cas.cz (M.B.); karolina.drogowska@jh-inst.cas.cz (K.D.-H.); \\ martin.kalbac@jh-inst.cas.cz (M.K.) \\ * Correspondence: otakar.frank@jh-inst.cas.cz
}

Received: 14 February 2020; Accepted: 19 March 2020; Published: 24 March 2020

\begin{abstract}
The heterostructures of two-dimensional (2D) and three-dimensional (3D) materials represent one of the focal points of current nanotechnology research and development. From an application perspective, the possibility of a direct integration of active 2D layers with exceptional optoelectronic and mechanical properties into the existing semiconductor manufacturing processes is extremely appealing. However, for this purpose, 2D materials should ideally be grown directly on 3D substrates to avoid the transferring step, which induces damage and contamination of the 2D layer. Alternatively, when such an approach is difficult—as is the case of graphene on noncatalytic substrates such as $\mathrm{Si}-$ inverted structures can be created, where the 3D material is deposited onto the 2D substrate. In the present work, we investigated the possibility of using plasma-enhanced chemical vapor deposition (PECVD) to deposit amorphous hydrogenated $\mathrm{Si}$ (a-Si:H) onto graphene resting on a catalytic copper foil. The resulting stacks created at different $\mathrm{Si}$ deposition temperatures were investigated by the combination of Raman spectroscopy (to quantify the damage and to estimate the change in resistivity of graphene), temperature-dependent dark conductivity, and constant photocurrent measurements (to monitor the changes in the electronic properties of a-Si:H). The results indicate that the optimum is $100{ }^{\circ} \mathrm{C}$ deposition temperature, where the graphene still retains most of its properties and the a-Si:H layer presents high-quality, device-ready characteristics.
\end{abstract}

Keywords: silicon; graphene; heterostructure; CVD

\section{Introduction}

The research on 2D materials, first of all on graphene (Gr), belongs to the most exciting areas in condensed matter physics. The possibility of realizing various heterostructures based on the combination of atomically thin layers with 3D counterparts offers a particularly encouraging playground to investigate and modulate electronic or optical properties. The combination of graphene (2D) with silicon (3D) has been intensively studied recently [1-16], as the formed graphene/silicon Schottky heterojunctions are believed to provide low-cost, ultrathin, and efficient electronic devices-for example, photodetectors or solar cells.

To realize a graphene/silicon heterostructure, chemical vapor-deposited (CVD) graphene is usually grown on a metal catalyst (for example, $\mathrm{Cu}, \mathrm{Ni}$, or $\mathrm{Pt}$ foil) and then transferred to a target 
silicon substrate by a sacrificial polymer-assisted method. Unfortunately, corrugations and cracks are formed, and the graphene layer can also be contaminated (by etchant and polymer residues) during the transfer process [17]. Therefore, commonly used transfer techniques (both dry and wet) using graphene-support polymers are not befitting for the assembly of device-quality silicon/graphene heterostructures, in particular not for industrial applications.

In this study, we propose an inverted course of action to produce graphene/silicon heterostructures, where a 2D material serves as a substrate for a-Si:H deposition performed by a well-known plasma-enhanced chemical vapor deposition (PECVD) process. The idea of silicon film deposition on CVD graphene has already been verified by Arezki et al. [18] and Lupina et al. [19]. However, in these cases, the graphene layer was transferred by polymer-assisted technique to $\mathrm{SiO}_{2} / \mathrm{Si}$ substrates before the PECVD process started. In our work, to evade a dubious interface and transfer-induced impurities, the a-Si:H films were grown straight on the CVD graphene-coated $\mathrm{Cu}$ foils. We interrogate a broad temperature series of PECVD deposition process $\left(25-260^{\circ} \mathrm{C}\right)$ to identify an optimum, where the defect-creation in graphene is minimized and, at the same time, the electrical conductivity of a-Si:H is maintained. We demonstrate PECVD of amorphous silicon as a feasible pathway for the production of superior graphene/silicon heterostructures that are not affected by the graphene transfer procedure.

\section{Materials and Methods}

The graphene monolayer was synthesized on copper catalyst substrate using a low-pressure (47 Pa) CVD setup [11]. The $\mathrm{Cu}$ foil $\left(7 \times 2 \mathrm{~cm}^{2}\right.$; Alfa Aesar) was first heated to $1273 \mathrm{~K}$ and annealed with the flow of $\mathrm{H}_{2} / \mathrm{Ar}$ mixture [50 standard cubic centimeter per min (sccm)] for $20 \mathrm{~min}$. Afterwards, $30 \mathrm{sccm}$ of methane, as a carbon precursor, was introduced in the chamber for the same time of $20 \mathrm{~min}$. Finally, the sample was cooled down to the room temperature. The quality of graphene was checked in each experiment by Raman spectroscopy (e.g., Figures S1 and S2, Supporting Information (SI)). The growth conditions specified above led to a continuous coverage of predominantly monolayer graphene with thicker adlayers of lateral dimensions usually not exceeding 2-3 $\mu \mathrm{m}$ [20]. Minor heterogeneities in the Raman peak positions (Figure S2, SI) correspond to the roughness and polycrystalline nature of the $\mathrm{Cu}$ foil [21]. The $\mathrm{Cu}$ foil with graphene was then quickly transferred in air to the PECVD chamber for a-Si:H deposition.

The intrinsic a-Si:H layers (approximately 20-nm-thick) were directly deposited on the graphene-Cu substrates $\left(1 \times 1 \mathrm{~cm}^{2}\right)$ by a conventional capacitively coupled PECVD operating at a plasma frequency of $40 \mathrm{MHz}$. The substrates were heated up to various temperatures ranging between $25^{\circ} \mathrm{C}$ and $260{ }^{\circ} \mathrm{C}$ and exposed to a glow discharge plasma of high-purity silane $(99.999 \%)$ and hydrogen $\left(99.99999 \%\right.$ ) gas mixture with an RF power density of $0.05 \mathrm{Wcm}^{-2}$ under a pressure of $70 \mathrm{~Pa}$. The total gas flow was set to $48 \mathrm{sccm}$. The a-Si:H film thickness was established ex situ with a Tencor Alpha-step 100 profilometer on a sample prepared during the same deposition run, but on a glass substrate.

Raman spectroscopy measurements were conducted on a LabRAM HR spectrometer (Horiba Jobin-Yvon) equipped with an Olympus BX-41 microscope $(100 \times$ objective, N.A. $=0.9)$ and with the laser spot not exceeding $1 \mu \mathrm{m}$ in diameter. For the excitation, a 633-nm (1.96-eV) laser with its power kept below $1 \mathrm{~mW}$ was used. To gather statistically relevant information, Raman mapping was conducted on the area comprising $30-40 \mu \mathrm{m}^{2}$ with 2- $\mu \mathrm{m}$ mapping step. The Raman spectrometer was calibrated using an external Si reference, namely, the $\mathrm{F}_{1 g}$ line at $520.5 \mathrm{~cm}^{-1}$. All evaluated Raman bands (D, G, $\mathrm{D}^{\prime}$, and 2D) were fitted by Lorentzian lineshapes.

Constant photocurrent measurement (CPM) and the temperature dependence of the dark conductivity were investigated on Corning glass (C7059) substrates with coplanar electrodes in a homemade setup equipped with a Keithley 237 source-measure unit. 


\section{Results and Discussion}

The synthesis of graphene-silicon heterostructures requires the deposition of a device-quality silicon film on a graphene layer, which can be done by PECVD. However, the PECVD deposition of the silicon thin film leads the graphene to be exposed to quite violent conditions, with elevated temperature and various plasma species.

The effects of the a-Si:H PECVD process on the graphene layer were examined by Raman spectroscopy (Figure 1). The Raman spectra of the graphene were acquired through a $\sim 20$-nm-thick a-Si:H film, which is sufficiently thin to get a reliable signal from the graphene beneath it. All the spectra exhibited a broad Raman band around $2200 \mathrm{~cm}^{-1}$, which was attributed to the Si-H bond. Additionally, all the spectra showed the G ("graphitic", at the frequency of $\sim 1580 \mathrm{~cm}^{-1}$ for suspended graphene, assigned to the phonon with $\mathrm{E}_{2 g}$ symmetry at the $\Gamma$ point) and $2 \mathrm{D}$ (second-order resonant process; dispersive, at $\sim 2660 \mathrm{~cm}^{-1}$ for 633-nm excitation) peaks, which are characteristic for a graphene monolayer [22,23]. Additionally, the spectra with the grown silicon layer exhibited the D (intravalley mode, dispersive, at $\approx 1330 \mathrm{~cm}^{-1}$ for 633 -nm excitation) and $\mathrm{D}^{\prime}$ (intervalley, $\approx 1615 \mathrm{~cm}^{-1}$ ) peaks, which are connected with the breaking of the inner symmetry (defects) of the graphene lattice [22,23].

The level of structural disorder in graphene-expressed as the distance between the defects $\left(L_{D}\right)$ or, inversely, the defect density $\left(n_{D}\right)$ — can be quantified through the intensity ratio between the $\mathrm{D}$ and G bands $\left(I_{D} / I_{G}\right)[24,25]$ :

$$
L_{D}^{2}\left(\mathrm{~nm}^{2}\right)=(1.8 \pm 0.5) \times 10^{-9} \lambda_{L}^{4}\left(\frac{I_{D}}{I_{G}}\right)^{-1}
$$

where $\lambda$ is the excitation wavelength. The relation between $L_{D}$ and $n_{D}$ can be approximated as $L_{D} \approx n_{D}^{-0.5}$. Note the difference between $L_{D}$ and the lateral domain size $\left(L_{a}\right)$, which is used to quantify disorder in $3 \mathrm{D}$ materials such as graphite $[26,27]$. However, the proposed protocol breaks down when $L_{D}$ or $L_{A}$ drop under a certain value $(\approx 2-3 \mathrm{~nm})$ [25-27]. For graphite, a three-stage model (a so-called amorphization trajectory) of the transition from the $\mathrm{sp}^{2}$ (graphitic) to the $\mathrm{sp}^{3}$ (tetrahedral) hybridized carbon atoms was introduced and tested [27]. In stage 1, the number of carbon vacancies increases, which is accompanied by the appearance and intensity increase of the D and D' bands, and a G band upshift. The defect density is directly proportional to $I_{D} / I_{G}$. In stage 2 , the defects start to coalesce and a greater amount of $\mathrm{sp}^{3}$ defects is observed as well (up to $20 \%$ by the end of stage 2 in graphite [27]). As the number of ordered aromatic rings decreases, the $\mathrm{D}$ band intensity is lowered too. Therefore, the defect density is inversely proportional to $I_{D} / I_{G}$ in stage 2 . While the relation $1 / n_{D} \propto I_{D} / I_{G}$ was empirically established for graphite, there is no precise enumeration for graphene due to the complex effects of different kinds of defects (vacancy, edgelike, $\mathrm{sp}^{3}$ ) on the defect bands [25,28]. Besides the $I_{D} / I_{G}$ drop, the $G$ band frequency $\left(\omega_{G}\right)$ in graphene decreases in stage 2; however, this is only when the amount of $\mathrm{sp}^{3}$ defects increases, not when the coalescence of vacancies takes place. Therefore, it is safer to utilize the width of the $\mathrm{G}$ band ( $\Gamma_{G}$, defined as full-width at half-maximum) along with $I_{D} / I_{G}$ to monitor the degree of disorder because the width will always increase regardless of the defect type [25]. 


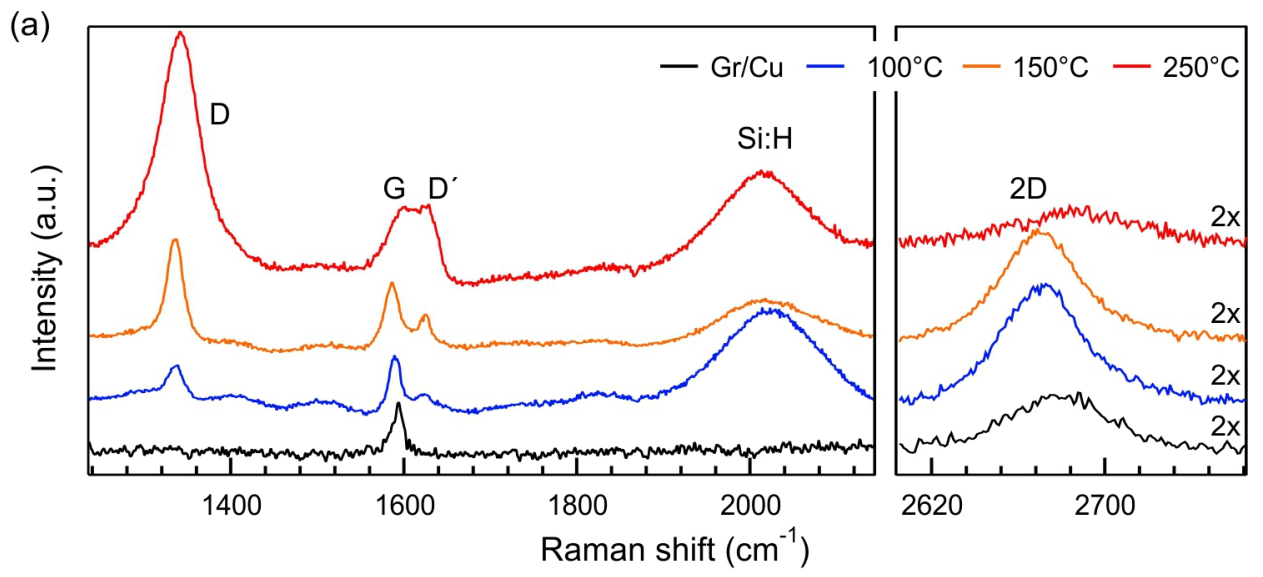

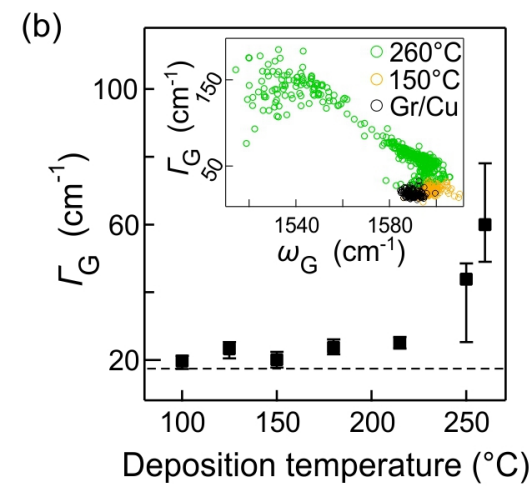

(d)

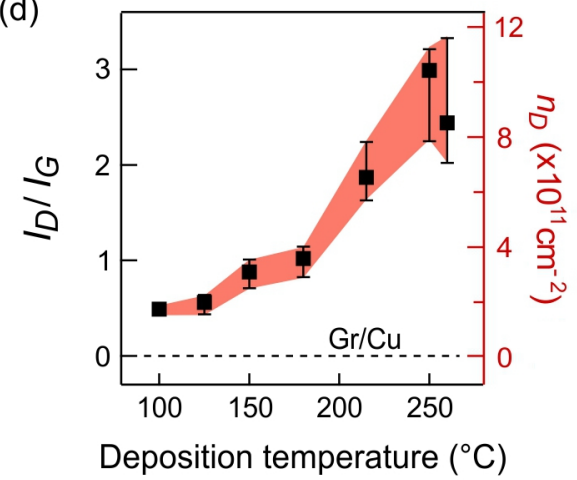

(c)

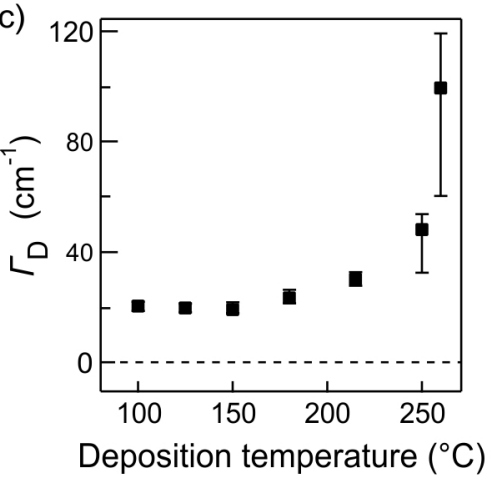

(e)

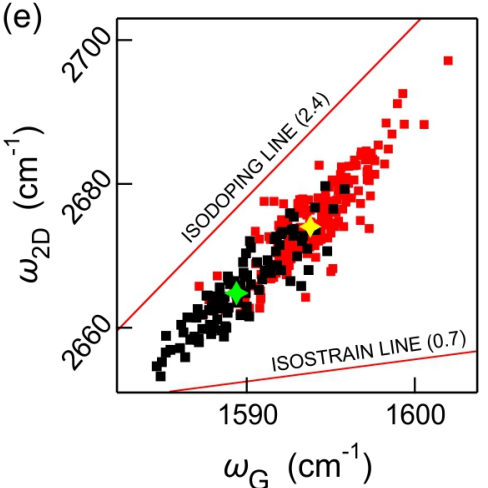

Figure 1. (a) Selected Raman spectra of as-grown graphene on the copper catalyst (black) and graphene with a-Si:H grown by plasma-enhanced chemical vapor deposition (PECVD) with deposition temperature in the range from $100{ }^{\circ} \mathrm{C}$ to $260^{\circ} \mathrm{C}$ (colored). Raman $2 \mathrm{D}$ bands are multiplied $2 \times$ for clarity. Spectra are normalized on the Raman $G$ band of graphene. $(\mathbf{b}, \mathbf{c})$ Evolution of $\Gamma_{G}$ and $\Gamma_{D}$, respectively, with increasing a-Si:H deposition temperatures. Inset in (b) shows correlation of $\Gamma_{G}$ with $\omega_{G}$ for selected deposition temperatures. (d) $I_{D} / I_{G}$ intensity ratios for increasing deposition temperature. Red-filled area indicates the estimated defect density according to Equation (1) (right axis). The spread of $n_{D}$ values is determined from the experimental error and the uncertainty from Equation (1). Horizontal dashed lines in (b-d) represent $\Gamma_{G}, \Gamma_{D}$, and $I_{D} / I_{G}$ median values for as-grown graphene; zero medians denote absence of the $\mathrm{D}$ band in the spectra. The data points in the main panels $b-d$ represent medians of the fitted values from Raman maps comprising at least 225 points; the error bars are the first and third quartiles of the data distributions. (e) Correlation plot of the G and 2D frequencies for all points obtained during Raman mapping of the as-grown graphene (black squares) and graphene with a-Si:H deposited at $100^{\circ} \mathrm{C}$ (red squares). Green and yellow asterisks mark medians of the datasets.

Figure 1a shows the evolution of the Raman spectra of graphene on $\mathrm{Cu}$ as a function of temperature at which a-Si:H is deposited (the Raman spectra for the whole series are depicted in Figure S1, SI). All 
the main peaks of graphene reflect the increasing level of disorder induced by the plasma deposition process: the $\mathrm{D}$ and $\mathrm{D}^{\prime}$ bands intensities increase, all the bands broaden, and the 2D band intensity decreases. The analysis of data obtained by Raman mapping shows the steady increase of $\Gamma_{G}$ and $\Gamma_{D}$, as is detailed in Figure $1 b, c$, respectively. The evolution of the $I_{D} / I_{G}$ parameter is plotted in Figure $1 d$, along with $n_{D}$ calculated according to Equation (1). As can be seen, the $I_{D} / I_{G}$ increases until the deposition temperature reaches $250-260{ }^{\circ} \mathrm{C}$. According to Equation (1), at this temperature, $n_{D}$ amounts to $\approx 4.5 \pm 2.5 \times 10^{11} \mathrm{~cm}^{-2}$, corresponding to $L_{D} \approx 10.3 \pm 1.6 \mathrm{~nm}$. While the $L_{D}$ value still points to stage 1 amorphization, all the fitted parameters abruptly increase, especially the widths (see Figure $1 b, c)$. In this case, the broadening of the bands is caused in part by the increasing disorder and in part by the more-pronounced heterogeneity. The inset in Figure $1 \mathrm{~b}$ shows that the G band significantly downshifts in many of the mapped points for the deposition temperature of $260{ }^{\circ} \mathrm{C}$. Such behavior is indicative of a large number of $\mathrm{sp}^{3}$ defects [27]. A certain degree of heterogeneity of the plasma-induced effects on graphene can be expected given the known variations of the reactivity of graphene depending on the $\mathrm{Cu}$ face it is resting on [29].

A deeper insight into the nature of the defects can be gained by looking at the ratio between the Raman intensities of the $\mathrm{D}$ and $\mathrm{D}^{\prime}$ bands $\left(I_{D} / I_{D^{\prime}}\right)$ that reflects the nature of the defects [28]. In all tested samples, where the $\mathrm{D}^{\prime}$ can be confidently fitted (i.e., starting at $125^{\circ} \mathrm{C}$ ), the median $I_{D} / I_{D^{\prime}}$ varies in the range of 2.0-3.8. Even though there is a steady increase of the values with temperature, the range is indicative of dominantly edgelike defects [28]. It can be surmised that the reactive species in the plasma first attack the lower energy sites at the existing edges and grain boundaries, which are known to be more reactive [30,31], thereby extending them. However, at $260{ }^{\circ} \mathrm{C}$, the spread of $I_{D} / I_{D^{\prime}}$ values increases rapidly, reaching even up to 8-9 in some cases, pointing to the appearance of vacancies or $\mathrm{sp}^{3}$ defects [28]. This corresponds to the observation of the $\mathrm{G}$ band downshift at $260{ }^{\circ} \mathrm{C}$ (see above).

It is known that the increasing disorder has adverse effects on the resistivity $(\rho)$ of graphene. Due to the nature of our experiment, it was not possible to measure the electrical properties of the graphene itself because the particular level and type of disorder is achieved only after the deposition of $\mathrm{Si}$, and its presence would, in turn, influence the measurement. However, there are numerous reports on the relation between $I_{D} / I_{G}$ (or $L_{D}, n_{D}$ ) and $\rho$ (or sheet resistance, $R_{S}$ ) [32,33]. In stage $1, \rho$ ranges from $\approx 600 \Omega$ of pristine CVD graphene to $\approx 20 \mathrm{k} \Omega$ [33]. For the $L_{D}$ range in our experiment, $\rho$ should be lower than $1 \mathrm{k} \Omega$ at a $100-{ }^{\circ} \mathrm{C}$ deposition temperature (with $L_{D}=24.1 \pm 3.1 \mathrm{~nm}$ ), and it should reach $\approx$ $3 \mathrm{k} \Omega$ at $250{ }^{\circ} \mathrm{C}$ (with $L_{D}=9.8 \pm 1.5 \mathrm{~nm}$ ).

The state of graphene in terms of charge-transfer doping and strain can also be evaluated from the correlation of $G$ and 2D frequencies. The method was introduced by Lee et al. [34] and has been utilized in various studies and settings ever since [35], including on graphene on $\mathrm{Si} / \mathrm{SiO}_{2}$ with a: Si-H deposited on top [19]. In brief, all the Raman data points (for example, from a map) are plotted in the $\omega_{2 D}, \omega_{G}$ phase space. Due to the different sensitivity of the $G$ and $2 D$ bands to strain and charge transfer, a secondary coordinate system is created with the origin estimated from suspended graphene and the axes generated from the benchmark experiments on graphene deformation and doping. The $\omega_{2 D}$ versus $\omega_{G}$ plots for the whole temperature series in our study are shown in Figure S2 (SI). Up to $\approx 200{ }^{\circ} \mathrm{C}$, the data points are spread in a mostly linear fashion in the $\omega_{2 D}, \omega_{G}$ plots; however, the slope of the line (fitted by least squares) gradually decreases from $\approx 2.2$ for bare graphene and, with a: Si-H deposited at $100{ }^{\circ} \mathrm{C}$, down to $\approx 1.3$ at $215^{\circ} \mathrm{C}$. The largest slope corresponds to the distribution of the data points only due to varying strain; the local charge carrier concentration does not significantly fluctuate, as is common for graphene on $\mathrm{Cu}$ [21]. A decreasing slope is indicative of the increasing influence of charge-transfer doping, related to the defect formation. At the highest temperatures, the distribution of the data points forms larger spreads in all directions, reflecting the great heterogeneity and high disorder in the lattice. The change in the $\omega_{2 D}, \omega_{G}$ distribution for the as-grown graphene and graphene with a-Si:H deposited at $100{ }^{\circ} \mathrm{C}$ is detailed in Figure 1e. The clouds of the data points shift only along the isodoping line; in other words, only the strain is changing. The difference between the median values of the two distributions corresponds to a biaxial compression 
of $\approx 0.07 \%$. In contrast to previous results of $\mathrm{Si}$ deposited on a graphene transferred to a $\mathrm{Si} / \mathrm{SiO}_{2}$ substrate [19], no change in doping was observed at this deposition temperature. We might ascribe the difference to the state of graphene before the Si deposition-without significant impurities in our case against the transferred graphene with possible remnants of the sacrificial polymer (in the case of Reference [19]).

The electronic quality of silicon films strongly depends on the fabrication conditions. To find the optimum temperature interval at which graphene and a-Si:H exhibit properties suitable for device implementation, a series of silicon films deposited at various temperatures was characterized by the temperature-dependent dark conductivity and the CPM. The silicon films are identical to those deposited on graphene; however, the deposition time had to be increased to obtain the roughly 500-nm-thick film needed for reliable electrical and optical measurements.

Figure 2a displays the Arrhenius plot of the temperature dependence of dark conductivity $\sigma_{d}$ of a-Si:H deposited at various temperatures on Corning glass substrates with two coplanar titanium electrodes separated by $1.6 \mathrm{~mm}$. These data are fitted to a singly activated conductivity, $\sigma_{d}=\sigma_{0} \exp \left(-E_{a} / k T\right)$, where $k$ is the Boltzmann constant and $E_{a}$ is the activation energy for electrical conduction. With the increase in a-Si:H deposition temperature, room temperature $\sigma_{d}$ increases and $E_{a}$ decreases, as shown in Figure $2 \mathrm{~b}$. More precisely, three areas of dependence of $\sigma_{d}$ on the substrate temperature during the a-Si:H deposition can be observed. At first, the dark conductivity increases with the increase in deposition temperature from room temperature to $100^{\circ} \mathrm{C}$. Then, the conductivity levels off at a value of $\approx 10^{-9} \mathrm{Scm}^{-1}$ for deposition temperatures in the range of $100-200{ }^{\circ} \mathrm{C}$. Finally, the dark conductivity rises again with the increase in deposition temperature above $200^{\circ} \mathrm{C}$.

(a) $10^{-4}$

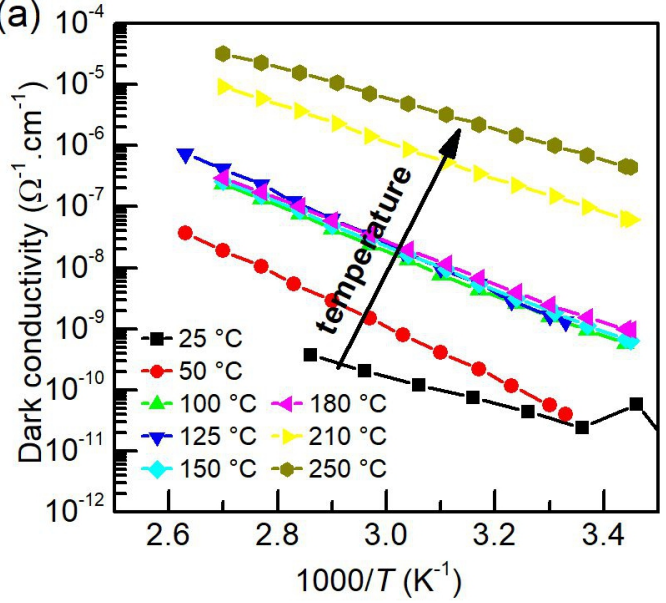

(b)

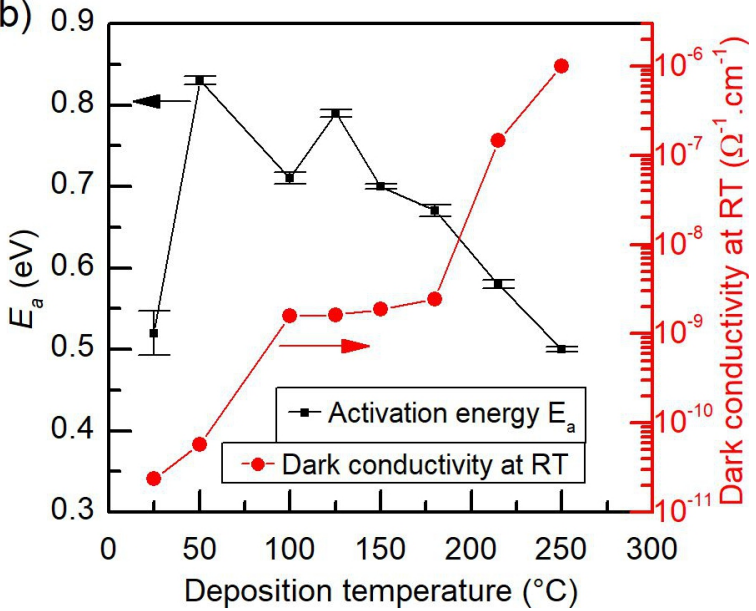

Figure 2. (a) Arrhenius plot of dark conductivity for a-Si:H films deposited at various temperatures in the range of $25^{\circ} \mathrm{C}$ to $250^{\circ} \mathrm{C}$; and (b) the dependence of activation energy $E_{a}$ and room-temperature dark conductivity on the deposition temperature (the error bars represent the standard error of the linear regression of the data sets in (a)). The lines between the points are drawn to guide the eye.

Figure 3 shows the CPM mid-gap absorption spectra and the absorption coefficient $\alpha$ for $1.2 \mathrm{eV}$ $[\alpha(1.2 \mathrm{eV})]$ of a-Si:H films deposited at various temperatures. The value of $\alpha(1.2 \mathrm{eV})$ is directly proportional to the concentration of deep-defects in a-Si:H, which are identified as the unsaturated (dangling) Si bonds [36]. The spectra were calibrated by transmission and reflection measurements. The value of $\alpha(1.2 \mathrm{eV})$ was calculated from the linear fit of the absorption spectra in the range 1.1-1.3 eV. From the calibration experiments [37], we can assign the absorption coefficient $\alpha(1.2 \mathrm{eV})$ value of $1 \mathrm{~cm}^{-1}$ to the dangling-bond density in the range of $2.4-5.0 \times 10^{16} \mathrm{~cm}^{-3}$ [38]. These defects serve as recombination centers for charge carriers, therefore, their densities are critical for solar cell properties [39], namely, open-circuit voltage and fill factor [36]. The device-quality a-Si:H is commonly considered to have a dangling-bond density of the order of $10^{15}-10^{16} \mathrm{~cm}^{-3}$ [36]. Hence, ideally, $\alpha(1.2 \mathrm{eV})$ should be approaching $0.1 \mathrm{~cm}^{-1}$. The absorption edge sharpness is the second important 
factor from a photovoltaic point of view. It is usually described by the so-called Urbach energy [40]. This parameter directly determines minimal losses in the open-circuit voltage in the finalized solar cell [41].
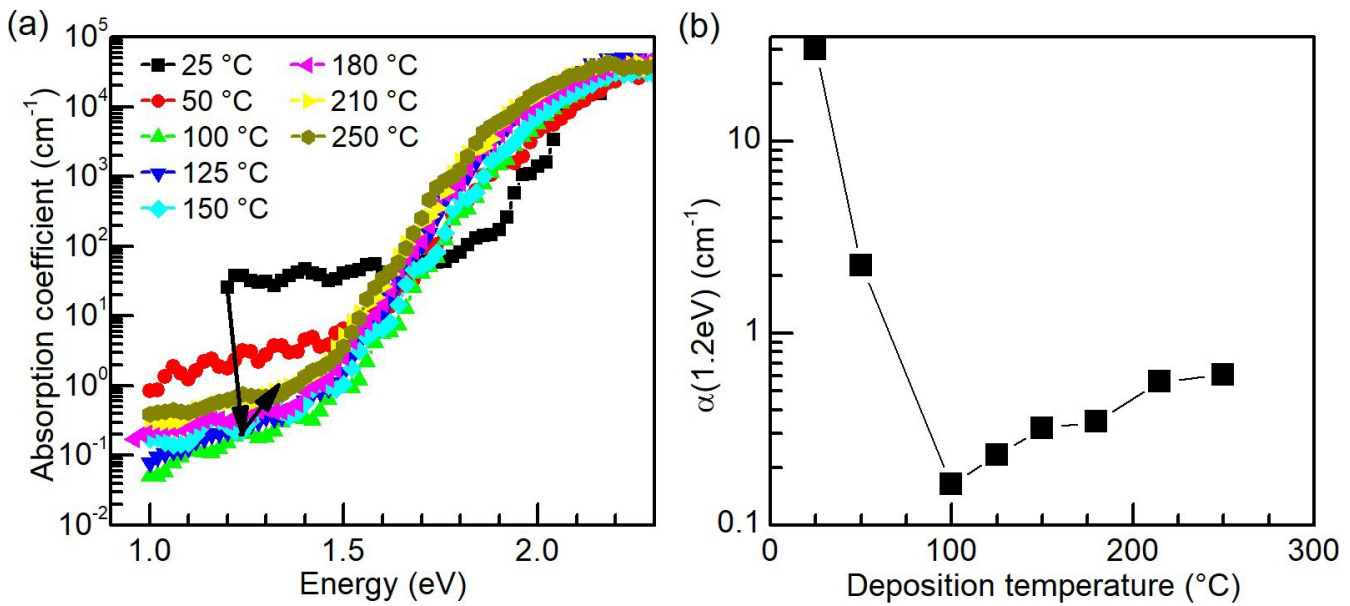

Figure 3. (a) Constant photocurrent measurement (CPM) measurement of mid-gap absorption of a-Si:H films deposited at various temperatures in the range of $25^{\circ} \mathrm{C}$ to $250{ }^{\circ} \mathrm{C}$; and (b) the dependence of the absorption coefficient $\alpha$ on the deposition temperature. The lines between the points are drawn to guide the eye.

As shown in Figure 3, the a-Si:H films deposited at temperatures below $100{ }^{\circ} \mathrm{C}$ show large deep-defect densities, as can be seen from the high mid-gap absorption. The silicon films deposited at temperatures at and above $100{ }^{\circ} \mathrm{C}$ exhibit similar Urbach energies $\left(E_{u}=50 \mathrm{meV}\right)$ and low deep-defect densities; however, the absorption coefficient $\alpha(1.2 \mathrm{eV})$ and thus the deep-defect density slowly increase again with the increase in the deposition temperature. As shown in Figure $3 b$, the optimum temperature of a-Si:H PECVD deposition can be found-from the viewpoint of dangling bond defect density-at $100{ }^{\circ} \mathrm{C}$. At this temperature, the $\sigma_{d}$ and $E_{a}$ are $\approx 10^{-9} \Omega^{-1} \mathrm{~cm}^{-1}$ and $0.7 \mathrm{eV}$, respectively (Figure 2), evincing the high-quality a-Si:H too. With respect to the Raman spectroscopy investigation, which showed only a minor change in the structural and electronic properties between the as-grown graphene and graphene with a-Si:H deposited at $100{ }^{\circ} \mathrm{C}$, it is obvious that this particular temperature represents the optimum under our experimental conditions.

\section{Conclusions}

The inverted heterostructure of silicon grown directly on graphene resting on the catalytic $\mathrm{Cu}$ foil holds great promise towards circumventing the disorder and impurities that are imposed on the graphene when using the common transfer procedures to place the graphene on top of the silicon. After a-Si:H deposition by the PECVD method, the thus induced changes in graphene were monitored by Raman spectroscopy, allowing a direct quantification of the defect density and relating the possible changes in resistivity. The electronic properties of a-Si:H were assessed by temperature-dependent dark conductivity and constant photocurrent measurements, from which the activation energy of electronic conduction and dangling-bond density can be derived, respectively. An optimum a-Si:H growth temperature of $100{ }^{\circ} \mathrm{C}$ permitted us to fabricate a device-quality inverted graphene/silicon stack with minor graphene disorder and good electronic properties of the a-Si:H film. To conclude, we validated the a-Si:H growth by PECVD as a suitable method for the production of inverted graphene/silicon heterostructures, which can be relevant not only for possible photovoltaic applications but also for the "silicon" industry in general.

Supplementary Materials: The following are available online at http:/ /www.mdpi.com/2079-4991/10/3/589/s1, Figure S1: Single-point Raman spectra of the whole series; Figure S2: Correlation plots of G and 2D frequencies for the whole series. 
Author Contributions: Conceptualization, A.F. and O.F.; methodology, M.M. and Z.H.; formal analysis, M.M. and M.B.; investigation, M.M., M.B., and K.D.-H.; writing-original draft preparation, M.M., M.B., Z.H., M.L., and O.F.; supervision, A.F., M.K., and O.F.; funding acquisition, A.F., M.K., and O.F. All authors have read and agreed to the published version of the manuscript.

Funding: This research was funded by Czech Science Foundation project GACR 17-18702S. This work was further supported by the Ministry of Education, Youth and Sports of the Czech Republic and The European Union-European Structural and Investments Funds in the frame of Operational Programme Research Development and Education project Pro-NanoEnviCz (Reg. No. CZ.02.1.01/0.0/0.0/16_013/0001821), by European Regional Development Fund; OP RDE; Project: "Carbon allotropes with rationalized nanointerfaces and nanolinks for environmental and biomedical applications" (No. CZ.02.1.01/0.0/0.0/16_026/0008382), and by CzechNanoLab research infrastructure supported by Ministry of Education, Youth and Sports of the Czech Republic through project LM2018110.

Conflicts of Interest: The authors declare no conflict of interest.

\section{References}

1. Song, Y.; Li, X.; Mackin, C.; Zhang, X.; Fang, W.; Palacios, T.; Zhu, H.; Kong, J. Role of Interfacial Oxide in High-Efficiency Graphene-Silicon Schottky Barrier Solar Cells. Nano Lett. 2015, 15, 2104-2110. [CrossRef]

2. Ye, Y.; Dai, L. Graphene-based Schottky junction solar cells. J. Mater. Chem. 2012, 22, 24224-24229. [CrossRef]

3. Sinha, D.; Lee, J.U. Ideal Graphene/Silicon Schottky Junction Diodes. Nano Lett. 2014, 14, 4660-4664. [CrossRef]

4. Lin, Y.; Li, X.; Xie, D.; Feng, T.; Chen, Y.; Song, R.; Tian, H.; Ren, T.; Zhong, M.; Wang, K.; et al. Graphene/semiconductor heterojunction solar cells with modulated antireflection and graphene work function. Energy Environ. Sci. 2013, 6, 108-115. [CrossRef]

5. An, X.; Liu, F.; Jung, Y.J.; Kar, S. Tunable Graphene-Silicon Heterojunctions for Ultrasensitive Photodetection. Nano Lett. 2013, 13, 909-916. [CrossRef] [PubMed]

6. Mohammed, M.; Li, Z.; Cui, J.; Chen, T.P. Junction investigation of graphene/silicon Schottky diodes. Nanoscale Res. Lett. 2012, 7, 302. [CrossRef] [PubMed]

7. An, Y.; Behnam, A.; Pop, E.; Bosman, G.; Ural, A. Forward-bias diode parameters, electronic noise, and photoresponse of graphene/silicon Schottky junctions with an interfacial native oxide layer. J. Appl. Phys. 2015, 118, 114307. [CrossRef]

8. Li, X.; Zhu, M.; Du, M.; Lv, Z.; Zhang, L.; Li, Y.; Yang, Y.; Yang, T.; Li, X.; Wang, K.; et al. High Detectivity Graphene-Silicon Heterojunction Photodetector. Small 2016, 12, 595-601. [CrossRef] [PubMed]

9. Kumar, R.; Varandani, D.; Mehta, B.R. Nanoscale interface formation and charge transfer in graphene/silicon Schottky junctions; KPFM and CAFM studies. Carbon 2016, 98, 41-49. [CrossRef]

10. Di Bartolomeo, A.; Luongo, G.; Giubileo, F.; Funicello, N.; Niu, G.; Schroeder, T.; Lisker, M.; Lupina, G. Hybrid graphene/silicon Schottky photodiode with intrinsic gating effect. 2D Mater. 2017, 4, 025075. [CrossRef]

11. Hájková, Z.; Ledinský, M.; Vetushka, A.; Stuchlík, J.; Müller, M.; Fejfar, A.; Bouša, M.; Kalbáč, M.; Frank, O. Photovoltaic characterization of graphene/silicon Schottky junctions from local and macroscopic perspectives. Chem. Phys. Lett. 2017, 676, 82-88. [CrossRef]

12. Rahova, J.; Sampathkumar, K.; Vetushka, A.; Ledinsky, M.; Hajkova, Z.; Fejfar, A.; Frank, O. Local Photovoltaic Properties of Graphene-Silicon Heterojunctions. Phys. Status Solidi B 2018, 255, 1800305. [CrossRef]

13. Rehman, M.A.; Roy, S.B.; Akhtar, I.; Bhopal, M.F.; Choi, W.; Nazir, G.; Khan, M.F.; Kumar, S.; Eom, J.; Chun, S.H.; et al. Thickness-dependent efficiency of directly grown graphene based solar cells. Carbon 2019, 148, 187-195. [CrossRef]

14. Suhail, A.; Pan, G.; Jenkins, D.; Islam, K. Improved efficiency of graphene/Si Schottky junction solar cell based on back contact structure and DUV treatment. Carbon 2018, 129, 520-526. [CrossRef]

15. Li, X.; Zhu, H.; Wang, K.; Cao, A.; Wei, J.; Li, C.; Jia, Y.; Li, Z.; Li, X.; Wu, D. Graphene-On-Silicon Schottky Junction Solar Cells. Adv. Mater. 2010, 22, 2743-2748. [CrossRef]

16. Fan, G.; Zhu, H.; Wang, K.; Wei, J.; Li, X.; Shu, Q.; Guo, N.; Wu, D. Graphene/Silicon Nanowire Schottky Junction for Enhanced Light Harvesting. ACS Appl. Mater. Int. 2011, 3, 721-725. [CrossRef]

17. Kang, J.; Shin, D.; Bae, S.; Hong, B.H. Graphene transfer: Key for applications. Nanoscale 2012, 4, 5527-5537. [CrossRef] 
18. Arezki, H.; Boutchich, M.; Alamarguy, D.; Madouri, A.; Alvarez, J.; Cabarrocas, P.R.i.; Kleider, J.P.; Yao, F.; Hee Lee, Y. Electronic properties of embedded graphene: Doped amorphous silicon/CVD graphene heterostructures. J. Phys. Condens. Matter 2016, 28, 404001. [CrossRef]

19. Lupina, G.; Strobel, C.; Dabrowski, J.; Lippert, G.; Kitzmann, J.; Krause, H.M.; Wenger, C.; Lukosius, M.; Wolff, A.; Albert, M.; et al. Plasma-enhanced chemical vapor deposition of amorphous Si on graphene. Appl. Phys. Lett. 2016, 108, 193105. [CrossRef]

20. Kalbac, M.; Frank, O.; Kavan, L. The control of graphene double-layer formation in copper-catalyzed chemical vapor deposition. Carbon 2012, 50, 3682-3687. [CrossRef]

21. Frank, O.; Vejpravova, J.; Holy, V.; Kavan, L.; Kalbac, M. Interaction between graphene and copper substrate: The role of lattice orientation. Carbon 2014, 68, 440-451. [CrossRef]

22. Malard, L.M.; Pimenta, M.A.; Dresselhaus, G.; Dresselhaus, M.S. Raman spectroscopy in graphene. Phys. Rep. 2009, 473, 51-87. [CrossRef]

23. Ferrari, A.C.; Basko, D.M. Raman spectroscopy as a versatile tool for studying the properties of graphene. Nat. Nanotechnol. 2013, 8, 235-246. [CrossRef] [PubMed]

24. Cancado, L.G.; Jorio, A.; Ferreira, E.H.M.; Stavale, F.; Achete, C.A.; Capaz, R.B.; Moutinho, M.V.O.; Lombardo, A.; Kulmala, T.S.; Ferrari, A.C. Quantifying Defects in Graphene via Raman Spectroscopy at Different Excitation Energies. Nano Lett. 2011, 11, 3190-3196. [CrossRef] [PubMed]

25. Lucchese, M.M.; Stavale, F.; Ferreira, E.H.M.; Vilani, C.; Moutinho, M.V.O.; Capaz, R.B.; Achete, C.A.; Jorio, A. Quantifying ion-induced defects and Raman relaxation length in graphene. Carbon 2010, 48, 1592-1597. [CrossRef]

26. Tuinstra, F.; Koenig, J.L. Raman Spectrum of Graphite. J. Chem. Phys. 1970, 53, 1126-1130. [CrossRef]

27. Ferrari, A.C.; Robertson, J. Interpretation of Raman spectra of disordered and amorphous carbon. Phys. Rev. B 2000, 61, 14095-14107. [CrossRef]

28. Eckmann, A.; Felten, A.; Mishchenko, A.; Britnell, L.; Krupke, R.; Novoselov, K.S.; Casiraghi, C. Probing the Nature of Defects in Graphene by Raman Spectroscopy. Nano Lett. 2012, 12, 3925-3930. [CrossRef]

29. Plšek, J.; Kovaříček, P.; Valeš, V.; Kalbáč, M. Tuning the Reactivity of Graphene by Surface Phase Orientation. Chem. Eur. J. 2017, 23, 1839-1845. [CrossRef]

30. Girit, C.; Meyer, J.C.; Erni, R.; Rossell, M.D.; Kisielowski, C.; Yang, L.; Park, C.H.; Crommie, M.F.; Cohen, M.L.; Louie, S.G.; et al. Graphene at the Edge: Stability and Dynamics. Science 2009, 323, 1705-1708. [CrossRef]

31. Bissett, M.A.; Izumida, W.; Saito, R.; Ago, H. Effect of Domain Boundaries on the Raman Spectra of Mechanically Strained Graphene. ACS Nano 2012, 6, 10229-10238. [CrossRef]

32. Vlassiouk, I.; Smirnov, S.; Ivanov, I.; Fulvio, P.F.; Dai, S.; Meyer, H.; Chi, M.F.; Hensley, D.; Datskos, P.; Lavrik, N.V. Electrical and thermal conductivity of low temperature CVD graphene: the effect of disorder. Nanotechnology 2011, 22. doi:10.1088/0957-4484/22/27/275716. [CrossRef] [PubMed]

33. Shlimak, I.; Haran, A.; Zion, E.; Havdala, T.; Kaganovskii, Y.; Butenko, A.V.; Wolfson, L.; Richter, V.; Naveh, D.; Sharoni, A.; et al. Raman scattering and electrical resistance of highly disordered graphene. Phys. Rev. B 2015, 91. doi:10.1103/PhysRevB.91.045414. [CrossRef]

34. Lee, J.E.; Ahn, G.; Shim, J.; Lee, Y.S.; Ryu, S. Optical separation of mechanical strain from charge doping in graphene. Nat. Commu. 2012, 3, 1024. [CrossRef] [PubMed]

35. Mueller, N.S.; Heeg, S.; Peña-Alvarez, M.; Kusch, P.; Wasserroth, S.; Clark, N.; Schedin, F.; Parthenios, J.; Papagelis, K.; Galiotis, C.; et al. Evaluating arbitrary strain configurations and doping in graphene with Raman spectroscopy. 2D Mater. 2018, 5, 015016. [CrossRef]

36. Wronski, C.R. Amorphous silicon technology: Coming of age. Sol. Energy Mater. Sol. Cells 1996, 41-42, 427-439. [CrossRef]

37. Vaněček, M.; Kočka, J.; Stuchlík, J.; Kožíšek, Z.; Štika, O.; Tříska, A. Density of the gap states in undoped and doped glow discharge a-Si:H. Sol. Energy Mater. 1983, 8, 411-423. [CrossRef]

38. Wyrsch, N.; Finger, F.; McMahon, T.J.; Vanecek, M. How to reach more precise interpretation of subgap absorption spectra in terms of deep defect density in a-Si:H. J. Non-Cryst. Solids 1991, 137-138, 347-350. [CrossRef]

39. Staebler, D.L.; Wronski, C.R. Reversible conductivity changes in discharge-produced amorphous Si. Appl. Phys. Lett. 1977, 31, 292-294. [CrossRef] 
40. De Wolf, S.; Holovsky, J.; Moon, S.J.; Löper, P.; Niesen, B.; Ledinsky, M.; Haug, F.J.; Yum, J.H.; Ballif, C. Organometallic Halide Perovskites: Sharp Optical Absorption Edge and Its Relation to Photovoltaic Performance. J. Phys. Chem. Lett. 2014, 5, 1035-1039. [CrossRef]

41. Ledinsky, M.; Schönfeldová, T.; Holovský, J.; Aydin, E.; Hájková, Z.; Landová, L.; Neyková, N.; Fejfar, A.; De Wolf, S. Temperature Dependence of the Urbach Energy in Lead Iodide Perovskites. J. Phys. Chem. Lett. 2019, 10, 1368-1373. [CrossRef] [PubMed]

(C) 2020 by the authors. Licensee MDPI, Basel, Switzerland. This article is an open access article distributed under the terms and conditions of the Creative Commons Attribution (CC BY) license (http://creativecommons.org/licenses/by/4.0/). 